\title{
Prioritization of risk situations in neuro-urology: guidelines from Association Française d'Urologie (AFU), Association Francophone Internationale des Groupes d'Animation de la Paraplégie (A.F.I.G.A.P.), Groupe de Neuro-urologie de Langue Française (GENULF), Société Française de Médecine Physique et de Réadaptation (SOFMER) and Société Interdisciplinaire Francophone d'UroDynamique et de Pelvi-Périnéologie (SIFUD-PP)
}

\author{
Claire Hentzen $^{1}(\mathbb{D}) \cdot$ Xavier Biardeau $^{2} \mathbb{D} \cdot$ Nicolas Turmel $^{1,3} \mathbb{D} \cdot$ Rebecca Haddad $^{1} \mathbb{D} \cdot$ Elsa Bey $^{4}$ (D) . \\ Gérard Amarenco $^{1}$ (D) Pierre Denys ${ }^{5}$ (D) . Véronique Phé ${ }^{6}$ (D) Marie Aimée Perrouin-Verbe ${ }^{7}$ (D) Benoit Peyronnet ${ }^{8}$. \\ Charles Joussain ${ }^{5}$ (D)
}

Received: 11 July 2021 / Accepted: 2 August 2021 / Published online: 17 August 2021

(c) The Author(s), under exclusive licence to Springer-Verlag GmbH Germany, part of Springer Nature 2021

\begin{abstract}
Purpose The current health crisis has drastically impacted patient management in many fields, including neuro-urology, leading to a mandatory reorganization. The aim of this work was to establish guidelines regarding the prioritization and optimal timing of each step of neurogenic lower urinary tract dysfunction management.

Methods A steering committee included urologists and physical medicine and rehabilitation practitioners. Based on a literature review and their own expertise, they established a comprehensive risk-situation list and built a risk scale, allowing multiple other experts to score each clinical situation. New recommendations were generated using a Delphi process approach. Results Forty-nine experts participated in the rating group. Among the 206 initial items, 163 were selected and divided into four domains, diagnosis and assessment, treatment, follow-up, and complications, and two sub-domains, general (applicable for all neurological conditions) and condition-specific [varying according to the neurological condition (spinal cord injury, multiple sclerosis, brain injury, Parkinsonism, dysraphism, lower motor neuron lesions)]. The resulted guidelines are expert opinions established by a panel of French-speaking specialists, which could limit the scalability of this work.

Conclusions The present multidisciplinary collaborative work generates recommendations which complement existing guidelines and help clinicians to reorganize their patients' list in the long term with a personalized medicine approach, in the context of health crisis or not.
\end{abstract}

Keywords COVID-19 · Guidelines $\cdot$ Neuro-urology $\cdot$ Practice management $\cdot$ Prioritization

Claire Hentzen

claire.hentzen.mpr@gmail.com

1 Department of Neuro-Urology, Sorbonne University, GRC 01, GREEN Group of Clinical REsEarch in Neurourology, AP-HP, Hôpital Tenon, 4, rue de la Chine, 75020 Paris, France

2 Department of Urology, University of Lille, Claude Huriez Hospital, CHU Lille, 59000 Lille, France

3 Rehabilitation department, Danièle Casanova Hospital, 93205 Saint Denis, France

$4 \quad$ Urology and Andrology Department, Nîmes University Hospital, University of Montpellier, Nîmes, France
5 Neurourology and Andrology Unit, Department of Physical Medecine and Rehabilitation, Raymond-Poincaré, AP-HP, Université Paris-Saclay, UMR 1179 Inserm, Paris, France

6 Department of Urology, Sorbonne University, AP-HP, Pitié-Salpêtrière Academic Hospital, Paris, France

7 Urology department, Hôtel Dieu Hospital, University of Nantes, Nantes, France

8 Department of Urology, University of Rennes, Rennes, France 


\begin{tabular}{|c|c|}
\hline \multicolumn{2}{|c|}{ Abbreviations } \\
\hline EAU & European Association of Urology \\
\hline AFU & French Association of Urology \\
\hline SOFMER & $\begin{array}{l}\text { French Society of Physical and Rehabilita- } \\
\text { tion Medicine }\end{array}$ \\
\hline SIFUD-PP & $\begin{array}{l}\text { French-speaking Interdisciplinary Society of } \\
\text { Urodynamics and Pelvi-Perineology }\end{array}$ \\
\hline GENULF & $\begin{array}{l}\text { French-speaking Neuro-Urology Working } \\
\text { Group }\end{array}$ \\
\hline AFIGAP & $\begin{array}{l}\text { International French-speaking Association of } \\
\text { Paraplegia }\end{array}$ \\
\hline ICS & International Continence Society \\
\hline MS & Multiple sclerosis \\
\hline NLUTD & Neurogenic lower urinary tract dysfunction \\
\hline PMR & Physical medicine and rehabilitation \\
\hline SCI & Spinal cord injured \\
\hline
\end{tabular}

\section{Introduction}

Management of patients with neurogenic lower urinary tract dysfunction (NLUTD) is well established; aiming to prevent complications and to improve patients' quality of life [1]. Before the COVID-19 pandemic, the guidelines of scientific societies focused on the initial assessment, the therapeutic management, and the long-term follow-up, mainly in spinal cord injured (SCI), multiple sclerosis (MS), and patients with dysraphism [2-4]. However, no specific timeline for each step of the management and no prioritization of risk situations have been included in the current existing guidelines.

The current health crisis has drastically impacted patient management in many fields, including neuro-urology, leading to a mandatory reorganization. To improve practices and to help setting priorities, scientific societies established recommendations in an emergency context to postpone a large majority of patients' assessment and non-urgent treatments [5-7]. Since the virus continues to spread, recommendations helping to reorganize the diagnosis, treatment, and follow-up of neuro-urological patients are required to prevent urological complications and to preserve patients' quality of life. The present work aimed to establish guidelines regarding the prioritization and optimal timing of each step of NLUTD management.

\section{Methods}

A steering committee with recognized expertise in neurourology was created, including urologists and physical medicine and rehabilitation (PMR) practitioners (Supplementary material 1 ). The ten members were involved in French-speaking scientific societies: AFU (French Association of Urology), SOFMER (French Society of Physical and Rehabilitation Medicine), SIFUD-PP (French-speaking Interdisciplinary Society of Urodynamics and Pelvi-Perineology), and GENULF (French-speaking Neuro-Urology Working Group). The role of the steering committee was to devise the comprehensive risk-situation list, build the risk scale for participants, score each clinical situation, and generate recommendations using a Delphi process.

\section{Generation of a comprehensive risk-situations list}

All risk factors for complications inherent to NLUTD, ranging from purely functional to life-threatening complications, were listed based on a systematic literature review conducted by the steering committee. The research was conducted in May 2020 using the Medline and Embase databases, without date limitation. All articles written in French or English were eligible. Only studies that considered the following outcomes were included: upper urinary-tract complications, hydronephrosis, chronic kidney disease, urinary-tract infections, urolithiasis, device erosion, device infection, death, anxiety/depression, social impairment, quality of life impairment. The complete research algorithm is described in Supplementary material 2 . Additional searches were included after the selection of the key articles.

Out of the 2036 articles selected (1937 articles from the literature review and 99 additional ones), 192 had a level of evidence $\geq 2 b$ according to the Oxford classification [8]. The steering committee drafted a list of 206 proposals depicting the various risk situations identified from their expertise and the literature review. Four domains were described: diagnosis, treatment, follow-up, and complications, and split between the members of the steering committee (Supplementary material 1). Two sub-domains were also established: general (applicable for all neurological conditions) and condition-specific [varying according to the neurological condition (spinal cord injury, multiple sclerosis, brain injury, Parkinsonism, dysraphism and lower motor neuron lesions)].

\section{Risk scale}

To define each situation's level of risk, we used the Global Risk Analyzing[9, 10]. Five levels of risk were defined, and the timing of healthcare for each level of risk was validated by a group of 16 experts using a Delphi process: no delay, less than 1 month, 1-6 months, 6-12 months, over 12 months (supplementary material 3 ).

\section{Delphi scoring}

The 206 propositions were divided into 5 groups with a balanced number of items, and split between the experts according to their field of competence. 
A panel of French-speaking specialists from different disciplines (urology, PMR, gynecology, and pediatric urology), with extensive neuro-urology experience, was selected and split into 5 groups to rank the proposals submitted by the steering group. All the experts were members of at least one of the following French-speaking scientific societies: AFIGAP (International French-speaking Association of Paraplegia), AFU, SOFMER, SIFUD-PP, and GENULF.

Experts were asked to grade the level of risk according to the aforementioned risk scale for clinical scenarios in the first rating round. If an inter-rater's agreement of $\geq 90 \%$ was reached, the proposition and the level of risk were accepted. Otherwise, the proposition with the predominantly designated level of risk was selected after validation by the steering committee and submitted to further rounds. From the second round, each expert rated individual propositions on a scale ranging from 1 (totally inappropriate proposal) to 7 (totally appropriate proposal). Agreement level was defined according to the French health authority recommendations to build Delphi-based guidelines [11]. The proposals for which an agreement was not reached during the two first rounds were submitted to a third round, and a fourth round if necessary, giving the median score for each as a feedback to the panel. The definitions of agreement are depicted in supplementary material 4 .

\section{Results}

\section{Scoring}

Forty-nine experts participated in the rating group. The experts were divided into different rating subgroups according to their subspecialty (Supplementary table 5).

Among the 206 initial proposals, 163 were accepted after the final rating process (Supplementary material 4).

\section{Guidelines}

\section{Diagnosis and initial assessment}

The initial assessment is an essential step of lower urinary tract symptoms management since it contributes to the diagnosis of an underlying neurological condition. No studies have been done to determine the timeframe in which patients with NLUTD should be assessed, and the potential harm resulting from an increase in this assessment time. Twenty-one general items and 4 SCI patient-specific items were validated after the Delphi process. The guidelines on initial assessment are reported in Table 1 and supplementary material 6 and 7.

\section{Treatment}

The neuro-urological treatment often combines the management of the bladder reservoir and of the voiding mechanism. Despite randomized controlled studies and well-established

Table 1 Diagnosis-general population

\begin{tabular}{|c|c|}
\hline Guidelines for a neuro-urological assessment in patients with NLUTD & Schedule \\
\hline $\begin{array}{l}\text { In a patient with urinary incontinence and a quality-of-life impairment and/or a restriction of participation, a neuro-urological assessment is recommended } \\
\text { (regardless of the modalities) within }\end{array}$ & 1 to 6 months \\
\hline $\begin{array}{l}\text { In a patient with neurological disease who experience sudden deterioration of the urinary symptoms, a neuro-urological assessment is recommended } \\
\text { (regardless of the modalities) within }\end{array}$ & $<1$ month \\
\hline $\begin{array}{l}\text { In a patient with neurological disease and voiding dysfunction or chronic urinary retention, a neuro-urological assessment is recommended (regardless of } \\
\text { the modalities) within }\end{array}$ & 1 to 6 months \\
\hline $\begin{array}{l}\text { Before the introduction of overactive bladder treatment in a patient with neurological disease, a neuro-urological assessment is recommended (regardless } \\
\text { of the modalities) within }\end{array}$ & 1 to 6 months \\
\hline $\begin{array}{l}\text { Before the treatment of urinary stress incontinence in a patient with neurological disease, a neuro-urological assessment is recommended (regardless of the } \\
\text { modalities) within }\end{array}$ & 1 to 6 months \\
\hline $\begin{array}{l}\text { In a patient with recurrent non-febrile urinary tract infections ( } \geqq 4 \text { episodes per year), a neuro-urological assessment is recommended (regardless of the } \\
\text { modalities) within }\end{array}$ & 1 to 6 months \\
\hline $\begin{array}{l}\text { In a patient with NLUTD who experience new perineal/vesical/pelvic pain, a neuro-urological assessment is recommended (regardless of the modalities) } \\
\text { within }\end{array}$ & $<1$ month \\
\hline In a patient with perineal pressure sore, a neuro-urological assessment is recommended (regardless of the modalities) within & $<1$ month \\
\hline $\begin{array}{l}\text { In a patient with impossibility to perform urethral catheterization (intermittent or change of indwelling catheter), a neuro-urological assessment is } \\
\text { recommended (regardless of the modalities) }\end{array}$ & $\begin{array}{l}\text { as a matter of } \\
\text { urgency }\end{array}$ \\
\hline In a patient with erectile dysfunction, a neuro-andrology consultation is recommended within & 1 to 6 months \\
\hline In a patient with ejaculatory dysfunction, a neuro-andrology consultation is recommended within & 1 to 6 months \\
\hline In a male patient with a procreation project, a neuro-andrology consultation is recommended within & 1 to 6 months \\
\hline In a female patient with sexual dysfunction, a neuro-sexology consultation is recommended within & 1 to 6 months \\
\hline $\begin{array}{l}\text { In a female patient with a procreation project, regardless of the micturition status and the neurological pathology, a pre-conception consultation is } \\
\text { recommended within }\end{array}$ & 1 to 6 months \\
\hline
\end{tabular}
recommended within

Bold: strong agreement; non-bold: relative agreement. The full table is available in supplementary material 6

NLUTD neurogenic lower urinary tract dysfunction 
treatment algorithms [1], there is not sufficient data in the literature to recommend the timing to initiate treatment of detrusor overactivity with a high level of evidence. For the voiding mechanism, evidence demonstrated that indwelling urethral catheters increased the risk of urological complications (urinary tract infections, lithiasis, bladder cancer, devastated bladder outlet) in patients with NLUTD. Urethral intermittent self-catheterization remains the best voiding modality for most patients with chronic urinary retention and should be introduced as soon as possible [12]. The scoring validated 18 general items and 39 condition-specific items. The guidelines on treatments are reported in Table 2 and supplementary material 8.

\section{Follow-up}

Follow-up is one of the cornerstones of NLUTD management. Some previous guidelines recommended an annual follow-up of SCI patients, patients with MS and dysraphism [2-4]. They are based on the "bladder risk factor" of urinary tract deterioration. The definition of a "high risk" bladder remains controversial. However, a cut-off of $40 \mathrm{cmH} 2 \mathrm{O}$ discriminating high vs low detrusor pressure and $20 \mathrm{ml} /$ $\mathrm{cmH} 2 \mathrm{O}$ dichotomizing lower or normal bladder compliance are mainly used [13, 14].

Despite this, no robust data is available to assess the optimal follow-up schedule in patients with NLUTD. The scoring validated 19 general items and 18 condition-specific items. The guidelines on follow-up are reported in Table 3 and supplementary material 9 and 10 .

\section{Complications}

NLUTD complications are numerous, including urinary tract infections, lithiasis, reflux and renal failure. In addition, specific complications should be addressed, such as sores, cognitive and functional impairment, and autonomic dysreflexia. There is no robust data available regarding the optimal timing to manage previous complications. The Delphi scoring validated 42 general items and 2 items specific to SCI patients. The guidelines on complications are reported in Table 4 and supplementary material 11 and 12 .

\section{Discussion}

To the best of our knowledge, the present work provides the first grading risk-situation guidelines in patients with NLUTD. In the existing guidelines established when the COVID-19 pandemic started, patients with NLUTD were barely considered, and often lumped together with functional urology, which was not considered as an emergency condition by a few scientific societies [7, 15-17]. Only the EAU [18, 19], the AFU [5], and the ICS[20] described the

Table 2 Treatment-general population

\begin{tabular}{|c|c|}
\hline Guidelines for treatment (general condition) the following propositions refer to patients with NLUTD & Schedule \\
\hline $\begin{array}{l}\text { In a patient with urinary symptoms with an impact on social, professional, or familial activities, a consultation to discuss a treatment } \\
\text { is recommended within }\end{array}$ & 1 to 6 months \\
\hline In a patient with urinary symptoms with an impact on thymic status, a consultation to discuss a treatment is recommended within & 1 to 6 months \\
\hline $\begin{array}{l}\text { In a patient with stress urinary incontinence with a significant impact on social, professional, or familial activities, and failure of } \\
\text { physical and physiotherapy training, a consultation to discuss a treatment is recommended within }\end{array}$ & 1 to 6 months \\
\hline $\begin{array}{l}\text { In a patient with stress urinary incontinence with a mild impact on social, professional or familial activities, and failure of physical } \\
\text { and physiotherapy training, a consultation to discuss a treatment is recommended within }\end{array}$ & 6 to 12 months \\
\hline $\begin{array}{l}\text { In a patient with stress urinary incontinence and risk of maceration or poor skin safety, and failure of physical and physiotherapy } \\
\text { training, a consultation to discuss a treatment is recommended within }\end{array}$ & $<1$ month \\
\hline $\begin{array}{l}\text { In a patient with acute and complete urinary retention (Male/Female) (secondary to a recent decompensation of NLUTD) managed } \\
\text { with a urethral indwelling catheter, a therapeutic education for intermittent catheterization in a specialized unit is recommended } \\
\text { within }\end{array}$ & $<1$ month \\
\hline $\begin{array}{l}\text { In a patient with acute and complete urinary retention (Male/Female) (secondary to recent decompensation of NLUTD) managed with } \\
\text { a suprapubic catheter, a therapeutic education for intermittent catheterization in a specialized unit is recommended within }\end{array}$ & $<1$ month \\
\hline $\begin{array}{l}\text { In a patient with acute and complete urinary retention (Male/Female) (secondary to recent decompensation of NLUTD) managed with } \\
\text { intermittent catheterization by a third, a therapeutic education for intermittent catheterization in a specialized unit is recommended } \\
\text { within }\end{array}$ & < 1 month \\
\hline $\begin{array}{l}\text { In a patient with bowel symptoms with an impact on social, professional, or familial activities, a consultation to discuss a treatment is } \\
\text { recommended within }\end{array}$ & 1 to 6 months \\
\hline In a patient with bowel symptoms with an impact on thymic status, a consultation to discuss a treatment is recommended within & 1 to 6 months \\
\hline In a patient with bowel symptoms that can impact bladder conditions, a consultation to discuss a treatment is recommended within & 1 to 6 months \\
\hline $\begin{array}{l}\text { In a patient with fecal incontinence and mobility and/or sensory disorders, a consultation to discuss a treatment is recommended } \\
\text { within }\end{array}$ & 1 to 6 months \\
\hline In a pregnant patient with NLUTD, a reassessment of the detrusor overactivity treatment is recommended within & 1 mоншы \\
\hline In a pregnant patient with NLUTD, a reassessment of infectious urinary risk is recommended within & $<1$ month \\
\hline In a pregnant patient with NLUTD, a reassessment of constipation treatment is recommended within & $<1$ month \\
\hline
\end{tabular}

Bold: strong agreement; Non-bold: relative agreement; NLUTD: Neurogenic Lower Urinary Tract Dysfunction

Bold: strong agreement; non-bold: relative agreement

NLUTD neurogenic lower urinary tract dysfunction 
Table 3 Follow-up-general population

Guidelines for follow-up (general condition) the following propositions refer to patients with NLUTD

After the introduction or modification of treatment for OAB without detrusor overactivity (drug, medical device, pelvic floor muscle training), a follow up (regardless of the modalities) is recommended within

After the introduction or modification of treatment for $\mathrm{OAB}$ with detrusor overactivity (drug, medical device, pelvic floor muscle

training), a follow up (regardless of the modalities) is recommended within

After the introduction or modification of treatment for low bladder compliance, a follow-up (regardless of the modalities) is recommended within

In a patient with neurological disease who just learned the use of a sheath / condom catheter, a follow-up (regardless of the modalities) is recommended within

In a patient with intermittent catheterization by a third, for whom no change in the micturition status has opted, a follow-up

(regardless of the modalities) is recommended within

In a patient with NLUTD and suprapubic catheter, for whom no change in the micturition status has opted, a follow-up (regardless of the modalities) is recommended within

After the post-surgery stabilization phase of a continent urinary diversion (Mitrofanoff, Monti, Casale), without any complication, a

follow-up (regardless of the modalities) is recommended within

After the post-surgery stabilization phase of an augmentation enterocystoplasty, a follow-up (regardless of the modalities) is recommended within

After the post-surgery stabilization phase of an external sphincterotomy, in a patient with reflex micturition who was operated on more than a year ago and is stable, a follow-up (regardless of the modalities) is recommended

After the post-surgery stabilization phase of an upper urinary tract lithiasis surgery, a follow-up (regardless of the modalities) is recommended within

In a patient with a cystectomy and urinary diversion for more than a year and no complication, a follow-up is recommended (regardless of the modalities) within

In a patient with a cystectomy and urinary diversion for a urethrocutaneous fistula with a pressure sore, it is recommended to reassess the sore healing within

In a pregnant patient with NLUTD, regardless of the micturition status and neurological pathology, a follow-up in an expert center with a multidisciplinary approach is recommended within

Bold: strong agreement; Non-bold: relative agreement; NLUTD: Neurogenic Lower Urinary Tract Dysfunction

Bold: strong agreement; non-bold: relative agreement. The full table is available in supplementary material 9

NLUTD neurogenic lower urinary tract dysfunction

Table 4 Complications-general population
Schedule

1 to 6 months

1 to 6 months

1 to 6 months

1 to 6 months

6 to 12 months

6 to 12 months

6 to 12 months

6 to 12 months

6 to 12 months

6 to 12 months

6 to 12 months

1 to 6 months

$<1$ month 
neurologic population and suggested a management schedule for these patients in times of health crisis. Our present guidelines are in accordance with many aspects to existing guidelines. However, several specific factors have been addressed, allowing a significant improvement in current recommendations.

Considering the initial assessment and the diagnosis, these new guidelines are consistent with existing recommendations, which suggest an early assessment in both congenital and acquired neurological diseases to diagnose NLUTD to prevent irreversible deterioration of the lower and upper urinary tract [21]. The optimal timeline was defined in SCI patients, with an assessment as soon as possible after the end of the spinal shock phase and urodynamic testing at 6 and 12 months after the initial injury. The GENULF suggested performing a urodynamic testing every six months [2] within the two first years. Based on the specificities of the neurological patients and their risk factors, we proposed individual guidelines and a schedule for assessment and treatment relative to each individual situation. For example, we recommended a neuro-urological assessment as a matter of emergency in the case of autonomic dysreflexia without any obvious etiology and a reassessment of the treatment efficacy in the following month in the case of identified neuro-urological cause.

The assessment following treatment would depend on the therapy. The delay to introduce a treatment has not been characterized in the literature until the COVID-19 pandemic, which has led to new recommendations to face this crisis. The scientific societies proposed to postpone patients' management with different delays depending on the severity of the pathology [5, 18-20]. In addition to these recommendations built for short time crisis, we propose a risk-level based timeframe for NLUTD management, applicable in a context of sanitary crisis or not. For example, a surgical alternative in case of refractory detrusor overactivity should be proposed within a month in SCI patients with high risk, but within 1 to 6 months in MS patients.

The follow-up has been well standardized. The ICS recommended annual urological monitoring, to detect complications and to adjust bladder management [22]. More specifically, Schurch et al. and the GENULF recommended in patients with dysraphism or spinal cord injury a yearly examination because of their "high-risk" bladder, which could be delayed by one to two years after attaining controlled NLUTD [2, 3]. De Sèze et al. recommended a cystometry every one to three years in MS patients [4]. In more general terms, the EAU recommended in "high-risk" patients, to assess upper urinary tract every 6 months and perform a physical and urine laboratory examination every year [21]. However, during the crisis, most of the scientific societies proposed postponing urodynamic assessment $[5,20]$. Only Goldman et al. proposed to assess neurogenic patients with urodynamic with up to 4 weeks of delay [23]. We recommend an assessment every 6-12 months in patients with initially "high risk" NLUTD, based on the urodynamics, regardless of the pathology. In patients with "low risk", this assessment should be done after 12 months.

Concerning emergency procedures, as previously recommended by all scientific societies, they should not be delayed. However, we also underscored SCI patients' specific complications which required urgent treatment such as Brindley device impairment or autonomic dysreflexia resulting from urolithiasis.

However, we must acknowledge several limitations to the present study. Indeed, the literature review has not been able to bring out enough data to drive recommendations with a high level of evidence. These guidelines are, therefore, an expert opinion. Moreover, these recommendations were established by a panel of French specialists, and some situations may not respond to another system of care, limiting the scalability of this work. Care organisation and resources should differ between countries, leading to difficulties to apply strictly these recommendations. However, due to the robust methodology and the exhaustiveness of the work, they shall help most clinicians to manage their patients.

\section{Conclusions}

This multidisciplinary collaborative work helped to establish recommendations which may be complementary with existing guidelines. By creating a comprehensive risk scale listing all relevant clinical situations encountered in neurourology, these recommendations would help clinicians to reorganize their patients' list in the long term with a personalized medicine approach, whatever is the situation.

Supplementary Information The online version contains supplementary material available at https://doi.org/10.1007/s00345-021-03804-4.

Acknowledgements We thank the SIRENE-Group for their participation in this work: Thierry Albert, Ania Bennour, Grégoire Capon, Evelyne Castel Lacanal, Audrey Charlanes, Emmanuel Chartier Kastler, Kathleen Charvier, Camille Chesnel, Jean Nicolas Cornu, Marianne De Sèze, Xavier Deffieux, Alexia Even, Alice Faure, Véronique Forin, Xavier Gamé, Anthony Gélis, Amandine Guinet-Lacoste, Jean François Hermieu, Marylène Jousse, Gilles Karsenty, Ammar Kassouha, Veronique Keppenne, Jacques Kerdraon, Pauline Lallemant, Eric Lapeyre, Frédérique Le Breton, Loïc Le Chapelain, Loïc Le Normand, Marc Lefort, Priscilla Leon, Anne Marie Leroi, Andrea Manunta, Reinier Opsomer, Bernard Paratte, Matthieu Peycelon, Brigitte Perrouin Verbe, Laurence Peyrat, Jean Gabriel Prévinaire, Bénédicte Reiss, Gilberte Robain, Thierry Roumeguère, Alain Ruffion, Christian Saussine, Brigitte Schurch, Jean Marc Soler, and Delphine Verollet.

Author contributions $\mathrm{CH}$ : protocol/project development, data collection or management, data analysis, and manuscript writing. XB: data collection or management, data analysis, and manuscript editing. NT: data collection or management, data analysis, and manuscript editing. 
RH: data collection or management, data analysis, and manuscript editing. EB: data collection or management, data analysis, and manuscript editing. GA: protocol/project development, data analysis, and manuscript editing. PD: protocol/project development, data analysis, and manuscript editing. VP: data analysis and manuscript editing. MAP-V: data collection or management, data analysis, and manuscript editing. BP: data collection or management, data analysis, and manuscript writing. CJ: data collection or management, data analysis, and manuscript writing.

Funding The author(s) received no financial support for the research, authorship, and/or publication of this article.

\section{Declarations}

Conflict of interest The authors have no conflict of interest.

Research involving human participants and/or animals No.

Informed consent Not applicable.

\section{References}

1. Nambiar A, Lucas M (2014) Chapter 4: guidelines for the diagnosis and treatment of overactive bladder $(\mathrm{OAB})$ and neurogenic detrusor overactivity (NDO). Neurourol Urodyn 33(Suppl 3):S21-25. https:// doi.org/10.1002/nau.22631

2. Ruffion A, de Sèze M, Denys P, Perrouin-Verbe B, Chartier-Kastler E, Groupe d'Etudes de Neuro-Urologie de Langue Française (2007) Groupe d'Etudes de Neuro-Urologie de Langue Française (GENULF) guidelines for the management of spinal cord injury and spina bifida patients. Progres En Urol J Assoc Francaise Urol Soc Francaise Urol 17:631-633. https://doi.org/10.1016/s1166-7087(07) 92379-9

3. Schurch B, Iacovelli V, Averbeck MA, Stefano C, Altaweel W, Finazzi AE (2018) Urodynamics in patients with spinal cord injury: a clinical review and best practice paper by a working group of the international continence society urodynamics committee. Neurourol Urodyn 37:581-591. https://doi.org/10.1002/nau.23369

4. de Sèze M, Ruffion A, Denys P, Joseph P-A, Perrouin-Verbe B, GENULF (2007) The neurogenic bladder in multiple sclerosis: review of the literature and proposal of management guidelines. Mult Scler Houndmills Basingstoke Engl 13:915-928. https://doi. org/10.1177/1352458506075651

5. Michel F, Gaillet S, Cornu JN, Robert G, Game X, Phé V et al (2020) French association of urology. COVID-19: recommendations for functional urology. Progres En Urol J Assoc Francaise Urol Soc Francaise Urol 30:414-425. https://doi.org/10.1016/j.purol.2020.04. 007

6. Amparore D, Campi R, Checcucci E, Sessa F, Pecoraro A, Minervini A et al (2020) Forecasting the future of urology practice: a comprehensive review of the recommendations by international and European associations on priority procedures during the COVID-19 pandemic. Eur Urol Focus 6:1032-1048. https://doi.org/10.1016/j. euf.2020.05.007

7. Gravas S, Fournier G, Oya M, Summerton D, Scarpa RM, Chlosta $P$ et al (2020) Prioritising urological surgery in the COVID-19 era: a global reflection on guidelines. Eur Urol Focus 6:1104-1110. https:// doi.org/10.1016/j.euf.2020.06.006

8. Oxford Centre for Evidence-Based Medicine: Levels of Evidence (March 2009)—Centre for Evidence-Based Medicine (CEBM), University of Oxford n.d. https://www.cebm.ox.ac.uk/resources/ levels-of-evidence/oxford-centre-for-evidence-based-medicinelevels-of-evidence-march-2009. Accessed 18 Mar 2021
9. Hudson P (2003) Applying the lessons of high risk industries to health care. Qual Saf Health Care 12(Suppl 1):i7-12. https://doi.org/ 10.1136/qhc.12.suppl_1.i7

10. Wilf-Miron R, Lewenhoff I, Benyamini Z, Aviram A (2003) From aviation to medicine: applying concepts of aviation safety to risk management in ambulatory care. Qual Saf Health Care 12:35-39. https://doi.org/10.1136/qhc.12.1.35

11. Haute Autorité de Santé (2010) Recommandations par consensus formalisé (RCF). Saint-Denis La Plaine: HAS

12. Gamé X, Phé V, Castel-Lacanal E, Forin V, de Sèze M, Lam O et al (2020) Intermittent catheterization: clinical practice guidelines from Association Française d'Urologie (AFU), Groupe de Neuro-urologie de Langue Française (GENULF), Société Française de Médecine Physique et de Réadaptation (SOFMER) and Société Interdisciplinaire Francophone d'UroDynamique et de Pelvi-Périnéologie (SIFUD-PP). Progres En Urol J Assoc Francaise Urol Soc Francaise Urol 30:232-251. https://doi.org/10.1016/j.purol.2020.02.009

13. Musco S, Padilla-Fernández B, Del Popolo G, Bonifazi M, Blok BFM, Groen J et al (2018) Value of urodynamic findings in predicting upper urinary tract damage in neuro-urological patients: a systematic review. Neurourol Urodyn 37:1522-1540. https://doi.org/ 10.1002/nau.23501

14. https://uroweb.org/wp-content/uploads/EAU-Guidelines-NeuroUrology-2015-v2.pdfn.d

15. Rodríguez-Covarrubias F, Castillejos-Molina RA, Autrán-Gómez AM (2020) Summary and considerations in genitourinary cancer patient care during the COVID-19 pandemic. Int Braz J Urol Off J Braz Soc Urol 46:98-103. https://doi.org/10.1590/S1677-5538. IBJU.2020.S115

16. Ficarra V, Novara G, Abrate A, Bartoletti R, Crestani A, De Nunzio $C$ et al (2020) Urology practice during the COVID-19 pandemic. Minerva Urol E Nefrol Ital J Urol Nephrol 72:369-375. https://doi. org/10.23736/S0393-2249.20.03846-1

17. Socarrás MER, Esperto F, Bapstistussi MD, Barufaldi F, Vital MS, Papalia R et al (2020) Endourology (Lithiasis). Management, surgical considerations and follow-up of patients in the COVID-19 era. Int Braz J Urol Off J Braz Soc Urol 46:39-49. https://doi.org/10. 1590/S1677-5538.IBJU.2020.S105

18. Ribal MJ, Cornford P, Briganti A, Knoll T, Gravas S, Babjuk M et al (2020) European association of urology guidelines office rapid reaction group: an organisation-wide collaborative effort to adapt the European association of urology guidelines recommendations to the coronavirus disease 2019 era. Eur Urol 78:21-28. https://doi. org/10.1016/j.eururo.2020.04.056

19. López-Fando L, Bueno P, Carracedo D, Averbeck M, Castro-Díaz DM, Chartier-Kastler E et al (2020) Management of female and functional urology patients during the COVID pandemic. Eur Urol Focus 6:1049-1057. https://doi.org/10.1016/j.euf.2020.05.023

20. Musco S, Del Popolo G, Lamartina M, Herms A, Renard J, Manassero A et al (2020) Neuro-urology during the COVID-19 pandemic: triage and priority of treatments. Neurourol Urodyn 39:2011-2015. https://doi.org/10.1002/nau.24460

21. Professionals S-O. EAU Guidelines: Neuro-Urology. Uroweb n.d. https://uroweb.org/guideline/neuro-urology/\#note_45. Accessed 27 May 2020

22. 6th ICI Book. ICS n.d. https://www.ics.org/education/icspublica tions/icibooks/6thicibook. Accessed 18 Mar 2021

23. Goldman HB, Haber GP (2020) Recommendations for tiered stratification of urological surgery urgency in the COVID-19 era. J Urol 204:11-13. https://doi.org/10.1097/JU.0000000000001067

Publisher's Note Springer Nature remains neutral with regard to jurisdictional claims in published maps and institutional affiliations. 